Research Article

\title{
Single-Phase Reactive Power Compensation Control for STATCOMs via Unknown System Dynamics Estimation
}

\author{
Cheng Guo $\mathbb{D}$, ${ }^{1}$ Linzhen Zhong $\mathbb{D}^{2},{ }^{2}$ Jun Zhao $\mathbb{D}^{2},{ }^{2}$ and Guanbin Gao $\mathbb{D}^{2}$ \\ ${ }^{1}$ Yunnan Electrical Power Experiment Institute Co., Kunming 650217, Yunnan, China \\ ${ }^{2}$ Faculty of Mechanical and Electrical Engineering, Kunming University of Science and Technology, Kunming 650500, China \\ Correspondence should be addressed to Guanbin Gao; gbgao@163.com
}

Received 20 March 2020; Accepted 22 April 2020; Published 9 May 2020

Guest Editor: Jian Huang

Copyright (c) 2020 Cheng Guo et al. This is an open access article distributed under the Creative Commons Attribution License, which permits unrestricted use, distribution, and reproduction in any medium, provided the original work is properly cited.

In this paper, a single-phase reactive power compensation control for static compensator (STATCOM) is developed. The primary novelty lies in that the reactive power compensation of STATCOM is reformulated as an equivalent tracking control for the reactive current, and a novel unknown system dynamics estimator (USDE) is also investigated to address the unknown system dynamics. A modeling phase based on a basic structure of single-phase STATCOM and the principle of STATCOM is first carried out to describe its behavior. To address the unknown dynamics and external disturbances, a new USDE is then developed, so that the modeling uncertainties and external disturbances can be accommodated without using a function approximator, where the demanding computational costs and tedious parameter tuning in the other control schemes are remedied. Finally, based on the proposed estimator, we design a composite control with a proportional integral (PI) feedback controller and the proposed estimator to achieve precise current tracking. The convergence analysis of both the estimation error and the control error is also given. Simulation results using a realistic simulator are presented to show the efficiency of the suggested strategy.

\section{Introduction}

To improve the power quality in the power systems, it is necessary to provide users with pollution-free power and make the voltage stable. However, the stability of voltage is usually affected by many factors, e.g., generation, transmission and distribution links, and nonlinear components in the power grids, all of which cause fluctuations in the grid voltage [1-3]. In addition, the low-voltage single-phase inductive loads are widely used in the modern power systems, such as electric vehicle charging pile and electric locomotive, etc., which will in turn increase the loss of reactive power in the power systems [4]. Therefore, it is important to study the single-phase dynamic reactive power compensation to improve the stability of power systems [5].

Reactive static compensator (STATCOM), shunt capacitor, synchronous condenser, and saturation reactor (SR) are all widely used in the reactive compensation devices. Compared with the traditional compensation devices, the STATCOM has the advantages of wide operational range, fast response speed, small capacity of energy storage elements, and control flexibility, and it can also compensate the reactive power in two directions [6]. Hence, it has become a modern reactive power compensation technology, which is attracting much research interest. STATCOM is usually connected in parallel with a $10 \mathrm{kV}$ power grid system, so that the multilevel technology becomes a key scheme of these types of devices applied in the high-voltage power grid system [7]. In the multilevel technology [8], the chain topology has become the mainstream structure because of its high degree of modularity, high equivalent switching frequency, redundant operation, and other advantages [9-13]. Direct-current (DC) side voltage balance is the premise of safe and reliable operation of chain STATCOM. Otherwise, the overvoltage of DC bus caused by imbalance will lead to the damage of the capacitor, burning of insulated gate bipolar transistor, and other serious faults, which will lead to the shutdown of the device, and seriously affect the safety and stability of the parallel grid. Therefore, many researchers [14-17] have proposed DC-side voltage balance control 
strategies for STATCOM with chain structure, photovoltaic grid connected inverter, power electronic transformer, and other devices.

In fact, the existing control methods for STATCOM include indirect current control [18], direct current control [19], sliding film variable structure control [20], and beat control [21], which use fully known system dynamics (i.e., nonlinear or linear dynamics). However, when we consider systems with unknown dynamics, nonlinearities, modeling errors, or disturbances, which are common in the power systems, it is not easy to design a controller to achieve satisfactory performance. Recently, U-model is proposed to address nonlinear system dynamics [22-25], which was originally developed by Zhu and Guo [26]. However, an accurate system model is again required in this framework. In the literature, the requirements on the system dynamics can be relaxed in terms of some disturbance estimation and rejection methods, e.g., high-gain observers $[27,28]$ and sliding mode observers $[29,30]$. Another efficient method to deal with the unknown system dynamics is the disturbance observer (DOB), which was originally reported in [31]. However, the early developed DOB is mainly suitable for linear systems only. In the subsequent studies, various advanced DOBs have been developed, such as nonlinear disturbance observer (NDO) [32], extended state observer (ESO) [33], and unknown input observer (UIO) [34]. However, the aforementioned observers require designing an observer, and they impose many parameters to be tuned, which may not be an easy task for practitioners. In this respect, it is worth to further investigate a new estimator with less tuning parameters and guaranteed convergence to address the unknown system nonlinearities for STATCOM control systems.

Based on the above discussion, this paper will develop a novel reactive power compensation method for STATCOM with fully unknown nonlinear dynamics and external disturbances. The reactive power compensation of STATCOM is reformulated as an equivalent tracking control for the required reactive current. Then, we construct a model of a single-phase STATCOM based on its physical structure and the principle of STATCOM. Moreover, a new constructive unknown system dynamic estimator (USDE) is developed to address the unknown disturbances and model uncertainties, so that the function approximator is not needed, and the demanding computational costs and tedious parameter tuning are remedied. Finally, a proportional integral (PI) controller is combined with the proposed estimator as a feedforward compensation to achieve satisfactory tracking control response, such that improved operation performance can be achieved. The convergence analysis of both the estimation error and control error is also given, which is also verified in terms of simulations based on a realistic STATCOM plant.

The major contributions of this paper include the following:

(1) The reactive power compensation of STATCOM is reformulated as an equivalent tracking control for the required reactive current. This allows developing advanced control strategies to achieve improved control performance.

(2) A novel USDE is developed to address the unknown system dynamics, modeling uncertainties, and external disturbances, where the function approximator is not needed, and thus, the demanding computational costs and complex parameter tuning are remedied. Different from the conventional DOB and other observers, this USDE has only one tuning parameter (the filter gain), and thus, it is easy to be implemented.

This paper is organized as follows: In Section 2, based on the structure of single-phase STATCOM and the principle of STATCOM, we construct a model to describe the behavior of the single-phase STATCOM. In Section 3, the proposed USDE, composite controller design and stability analysis are provided. Simulation results are given in Section 4, and some conclusions are drawn in Section 5.

\section{Preliminaries and Problem Formulation}

2.1. Structure of Single-Phase STATCOM. The main circuit structure of STATCOM can be generally divided into two types (i.e., voltage bridge circuit and current bridge circuit). In this paper, the STATCOM of single-phase voltage bridge circuit is considered as the research object to complete the reactive power compensation, since it has been used in many power system applications. Figure 1 shows the basic structure of single-phase STATCOM [7], which mainly includes the following three parts.

2.1.1. Voltage Source Converter (VSC). In the voltage source converter, the AC-side output is connected to the power grid, which is also composed of two pairs for bridge arms in parallel, where each pair of bridge arms is connected with two insulated gate bipolar transistors (IGBTs) power switches in series, and each IGBT is connected with one fast recovery diode in reverse parallel. The main purpose of the VSC is to produce an AC voltage from a DC voltage. Therefore, it is commonly referred to a DC-AC converter.

2.1.2. Capacitor. The direct-current (DC) capacitor is used to store energy and provide voltage for the VSC.

2.1.3. Coupling Reactor. Besides filtering out the possible high-order harmonics in the inverter output voltage, the reactor can be used to connect the voltage source between the converter side and the grid side.

2.2. Principle of STATCOM. According to the reactor dynamics, the self-commutating bridge circuit is connected with the power grid. Therefore, the circuit can generate or absorb the current by adjusting the phase or amplitude of the output voltage on the AC side of the bridge circuit properly or directly controlling the current on the AC side of the bridge circuit, so as to realize dynamic reactive power 


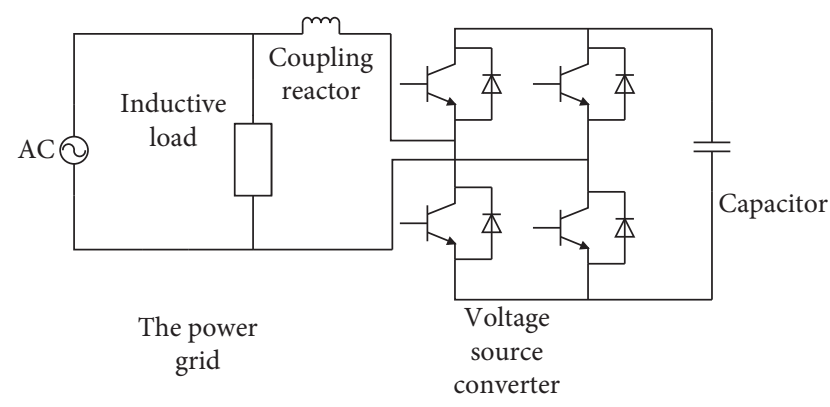

FIgURE 1: Structure of single-phase STATCOM.

compensation [9-13]. Moreover, the working principle of STATCOM can be represented by the equivalent circuit given in Figure 2.

In Figure 2, $\vec{U}_{S}$ is the power grid voltage and $\vec{U}_{I}$ is the output AC voltage of STATCOM. The voltage $\vec{U}_{L}$ of reactor is the difference between $\vec{U}_{S}$ and $\vec{U}_{I}$, and $\vec{I}$ is the current absorbed by STATCOM from the power grid. It should be noted that $\vec{U}_{S}, \vec{U}_{I}$, and $\vec{U}_{L}$ are the vectors of $U_{S}, U_{I}$, and $U_{L}$, respectively.

As shown in Figure 3, when $\vec{U}_{I}$ is larger than $\vec{U}_{S}$, the current is $90^{\circ}$ ahead of the power grid voltage, and the STATCOM provides reactive power to the system. When $\vec{U}_{I}$ is less than $\vec{U}_{S}$, the current lags behind the power grid voltage $90^{\circ}$, and the STATCOM absorbs reactive power from the system.

2.3. Modeling of Single-Phase STATCOM. From Figure 2, we can obtain the voltage current equation as

$$
U_{S}-U_{I}=R I+L \frac{\mathrm{d} I}{\mathrm{~d} t}
$$

Then, the system quickly detects the reactive current. Through appropriate control, the STATCOM output corresponds to the reactive compensation current. To detect the reactive current in the load, the instantaneous reactive power theory [35] is used to construct the single-phase system into a three-phase system.

By taking $I$ as $I_{a}$, delaying $I$ by $\pi /(3 \omega)$ and reversing it, we have the c-phase load current $I_{c}$. Using the sum of threephase current as 0 , we can obtain the b-phase load current $I_{b}$ as

$$
I_{b}=-I_{a}-I_{c} .
$$

The equivalent $d$ - $q$ transformation is used for the threephase current. Without loss of generality, we assume that $d$ axis coincide with the grid voltage vector. We can get the following equation:

$$
\left[\begin{array}{c}
I_{d} \\
I_{q}
\end{array}\right]=C_{a b c 2 d q}\left[\begin{array}{lll}
I_{a} & I_{b} & I_{c}
\end{array}\right]^{T},
$$

where $I_{d}$ and $I_{q}$ are the active and reactive components of three-phase current, $C_{a b c 2 d q}$ is the transformation matrix:

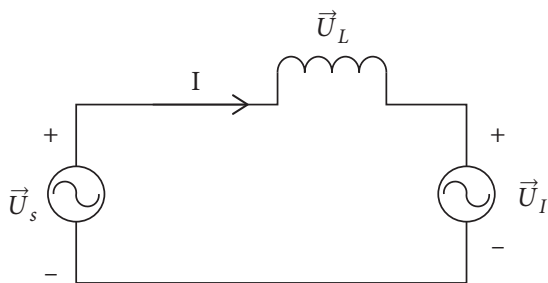

Figure 2: Equivalent circuit of single-phase STATCOM with the system.

$$
C_{a b c 2 d q}=\frac{2}{3}\left[\begin{array}{ccc}
\sin (\omega t) & \sin \left(\frac{\omega t-2 \pi}{3}\right) & \sin \left(\frac{\omega t-2 \pi}{3}\right) \\
\cos (\omega t) & \cos \left(\frac{\omega t-2 \pi}{3}\right) & \cos \left(\frac{\omega t-2 \pi}{3}\right)
\end{array}\right] .
$$

After obtaining the reactive current $I_{q}$ of the load, we can take it as the reference value of STATCOM to compensate the reactive current. Furthermore, model (1) can be rewritten as follows:

$$
\dot{I}=-\frac{R}{L} I-\frac{U_{S}}{L}+\frac{U_{I}}{L}=b U_{I}-d,
$$

where $b=(1 / L)$ and $d=(R / L) I+\left(U_{S} / L\right)$ are the control gain and the lumped disturbances. In addition, $U_{I}$ is the control signal in (5). It is noted that $d$ includes the system dynamics stemming from the unavoidable disturbances and load variations in the power systems. Without loss of generality, we assume that the derivative of $d$ is bounded, i.e., $\sup _{t \geq 0}|\dot{d}| \leq \zeta$ holds for a constant $\zeta>0$. Hence, the aim is to design a proper control such that the current $I$ can track the reference $I_{q}$.

Remark 1. In some existing results for STATCOM control designs, the system dynamics are assumed to be fully known. Since $U_{s}$ and $I$ in equation (5) are the dynamic variables, we can consider this part (i.e., variable $d$ ) as a total disturbance to be compensated in the control design, which will greatly reduce the melding effort and improve the current tracking effect. In this line, the classical methods to handle unknown dynamics, such as high-gain observers [27, 28] and sliding mode observers $[29,30]$, may impose heavy computational costs and achieve poor convergence (e.g., chattering), leading to difficulties in practical applications. Another efficient method to deal with the uncertainties is the disturbance observer (DOB) [31]. However, the early developed DOB is mainly suitable for linear systems only. Although various advanced DOBs have been developed, such as nonlinear disturbance observer (NDO) [32], extended state observer (ESO) [33], and unknown input observer (UIO) [34], the aforementioned observers require to design an observer, and they impose many parameters to be tuned, which may not be an easy task for practitioners. To remedy this issue, this paper provides an alternative USDE, which has the same function as DOB, but a simpler structure and one tuning parameter only. 


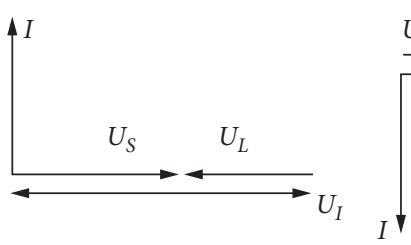

(a)

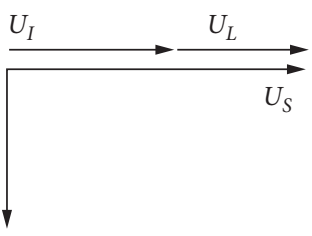

(b)

FIGURE 3: Single-phase STATCOM work vector diagram. (a) Current lead. (b) Current hysteresis.

\section{Composite Current Control with Unknown System Dynamics Estimator}

3.1. Unknown System Dynamics Estimator. In order to handle the lumped unknown dynamics in system (5), we will propose a novel USDE, which can estimate $d$ by using the measured input and output. For this purpose, we define $I_{f}$ and $U_{I f}$ as the filtered variables of $I$ and $U_{I}$ as

$$
\begin{cases}k \dot{I}_{f}+I_{f}=I, & I_{f}(0)=0, \\ k \dot{U}_{I f}+U_{I f}=U_{I}, & U_{I f}(0)=0,\end{cases}
$$

where $k>0$ is a constant parameter denoting the bandwidth of the adopted low-pass filter.

The principle of invariant manifold will be explored to design the estimator. In this line, we first introduce the following result.

Lemma 1 (see [36, 37]). Consider system (5) and filter operation (6), a variable is defined as

$$
\beta=\frac{I-I_{f}}{k}-\left(b U_{I_{f}}-d\right) .
$$

Then, this variable is bounded for any finite constant $k>0$ and converges to zero exponentially, that is,

$$
\lim _{k \rightarrow 0}\left[\lim _{t \longrightarrow \infty}\left\{\left(\frac{I-I_{f}}{k}\right)-\left(b U_{I f}-d\right)\right\}\right]=0 .
$$

Proof. From (6) and (7), the time derivative of $\beta$ is given by

$$
\dot{\beta}=\frac{\dot{I}-\dot{I}_{f}}{k}-\left(b \dot{U}_{I f}-\dot{d}\right)=-\frac{1}{k}(\beta-k \dot{d}) .
$$

Select a Lyapunov function as $V_{\beta}=(1 / 2) \beta^{2}$ such that

$$
\dot{V}_{\beta}=-\frac{1}{k} \beta^{2}+\beta \dot{d}
$$

According to Young's inequality, we have

$$
\beta \dot{d} \leq \frac{1}{2 k} \beta^{2}+\frac{k}{2} \dot{d}^{2}
$$

Substituting (11) into (10), we can get the following inequality:

$$
\begin{array}{r}
\dot{V}_{\beta} \leq-\frac{1}{k} \beta^{2}+\frac{1}{2 k} \beta^{2}+\frac{k}{2} \dot{d}^{2} \\
\leq-\frac{1}{k} V_{\beta}+\frac{k}{2} \zeta^{2} .
\end{array}
$$

By solving inequality (12), one can easily verify that $V_{\beta}(t) \leq e^{-t / k} V_{\beta}(0)+k^{2} \zeta^{2} / 2$. Thus, $\beta(t)$ will converge to a small compact set bounded by $|\beta(t)|=\sqrt{2 V_{\beta}(t)} \leq \sqrt{e^{-t / k} \beta^{2}(0)+k^{2} \zeta^{2}}$, where its size is determined by the filter parameter $k$ and the upper bound $\zeta$ of $d$, i.e., $\lim _{t \rightarrow \infty} \beta(t)=k \zeta$, which vanishes for sufficiently small $k$ and/or $d$ (i.e., $d=0$ ). This completes the proof.

The above ideal invariant manifold provides a mapping from the measured variable $I_{f}$ and $U_{I f}$ to the unknown system dynamics $d$. Thus, it can be used to design an estimator for $d$, which is given by

$$
\widehat{d}=b U_{I f}-\frac{I-I_{f}}{k} .
$$

Clearly, only the scalar constant $k>0$ used in the filter should be selected by the designer, which is a trivial task in comparison to the existing ESO and DOB methods.

Now, we have the following results:

Theorem 1. (see [36, 37]). For system (5) with unknown system dynamics estimator (13), the estimation error $e_{F}=$ $d-\widehat{d}$ is bounded by $\left|e_{F}(t)\right| \leq \sqrt{e_{F}^{2}(0) e^{-t / k}+k^{2} \zeta^{2}}$ and thus $d \longrightarrow \widehat{d}$ holds for $k \longrightarrow 0$ and/or $\zeta=0$.

Proof. After applying the filter operation $1 /(k s+1)$ on the both sides of (5), we can get

$$
\dot{I}_{f}=b U_{I f}-d_{f},
$$

Substituting the first equation of (6) into (14), we get

$$
d_{f}=b U_{I f}-\frac{I-I_{f}}{k} .
$$

Comparing (13) with (15), it is easy to find $\widehat{d}=d_{f}$. Therefore, the estimation error can be derived as

$$
e_{F}=d-\widehat{d}=d-d_{f} \text {. }
$$

To facilitate the proof, we further derive the derivative of the estimation error in (13) as

$$
\dot{e}_{F}=\dot{d}-\dot{\vec{d}}=\dot{d}-\frac{1}{k}\left(d-d_{f}\right)=\dot{d}-\frac{1}{k} e_{F} .
$$


Obviously, the estimation error can be very small, when a sufficiently small $k$ is used. To show this point, a Lyapunov function can be selected as $V=e_{F}^{2} / 2$, and its derivative can be calculated as

$$
\dot{V}=e_{F} \dot{e}_{F}=-\frac{1}{k} e_{F}^{2}+e_{F} \dot{d}
$$

According to Young's inequality, we have

$$
e_{F} \dot{d} \leq \frac{e_{F}^{2}}{2 k}+\frac{k \dot{d}^{2}}{2} \text {. }
$$

Substituting (19) into (18), we can get the following inequality:

$$
\dot{V}=e_{F} \dot{e}_{F}=-\frac{1}{k} e_{F}^{2}+e_{F} \dot{d} \leq-\frac{1}{k} V+\frac{k}{2} \zeta^{2} .
$$

Hence, one can calculate the solution of inequality (20) as $V(t) \leq e^{-t / k} V(0)+k^{2} \zeta^{2} / 2$, which further implies that the estimation error is bounded by $\left|e_{F}(t)\right| \leq \sqrt{e_{F}^{2}(0)^{-t / k}+k^{2} \zeta^{2}}$, and thus, we can claim $e_{F}(t) \longrightarrow 0$ for $k \longrightarrow 0$ and/or $\zeta=0$. This completes the proof.

Remark 2. From the above analysis, we know that the unknown system dynamics can be estimated accurately by constructed USDE (13). It is noted that the proposed USDE only imposes the filter operations given in (6) and algebraic calculation given in (13). Moreover, only the filter gain $k$ in (6) needs to be set by the designers. Hence, the structure of USDE is simple and its implementation is straightforward.

3.2. Composite Control Design Based on USDE. In this section, the aforementioned estimator will be introduced into the control design for system (5) to achieve current tracking. Furthermore, we will use the estimated term $\widehat{d}$ in (13) as an extracompensator superimposed on the PI control to design a new composite current control for the STATCOM plant. The composite control with the proposed USDE together with a PI control [38] is shown in Figure 4.

Let $I_{q}$ denote the reference current signal $I_{\text {ref }}$. The current tracking error is defined as follows:

$$
e=I_{\text {ref }}-I \text {. }
$$

To reduce the tracking error $e$, the controller can be designed as

$$
U_{I}=b\left[k_{p} e+k_{i} \int_{0}^{t} e(\tau) \mathrm{d} \tau+\hat{d}\right] .
$$

where $U_{I}$ is the output AC voltage of STATCOM, $k_{p}>0$ and $k_{i}>0$ denote the effect of the proportional and integral gains. $\hat{d}$ is a newly added compensation in addition to the feedback control part given in (13).

It is clear that the first part is the PI control, which is used to retain the stability of the controlled system, while the second term is the estimate of unknown dynamics to achieve satisfactory tracking response. Hence, the stability of the proposed control system with the estimator and composite control and the convergence of estimation and control errors can be summarized in the following.

Theorem 2. If composite control (22) with estimator (13) is applied for STATCOM system (2), the current tracking error $e$ and the estimation error $e_{F}$ will converge to a small compact set around zero, and $I$ can track the desired reference $I_{r e f}$ detected by the system.

Proof. By deriving (21) and substituting (22) into (5), the following equation can be obtained:

$$
\begin{aligned}
\dot{e}= & d-\widehat{d}-k_{p} e-k_{i} \int_{0}^{t} e(\tau) \mathrm{d} \tau \\
& =e_{F}-k_{p} e-k_{i} \int_{0}^{t} e(\tau) \mathrm{d} \tau,
\end{aligned}
$$

which can be rewritten as

$$
\dot{e}=e_{F}-k_{p} e-k_{i} e_{i}
$$

where $e_{i}=\int_{0}^{t} e(\tau) \mathrm{d} \tau$. To cope with the integral term $e_{i}$, we define the augmented error vector as $E=\left[\begin{array}{ll}e_{i} & e\end{array}\right]^{T}$ and select an augmented Lyapunov function as $V=(1 / 2) E^{T} P E+(1 / 2) e_{F}^{2}$ for a positive symmetric matrix $P$. Then, (24) can be written as

$$
\dot{E}=\left[\begin{array}{rr}
0 & 1 \\
-k_{i} & -k_{p}
\end{array}\right] E+\left[\begin{array}{l}
0 \\
1
\end{array}\right] e_{F}=A E+B e_{F} .
$$

The preconfigured PI control gains $k_{p}$ and $k_{i}$ are set to retain the stability of the control system, such that the matrix $A$ can guarantee that the error system $\dot{E}=A E$ is exponentially stable. Then, based on the Lyapunov theory, there exist positive definite symmetric matrices $P>0$ and $Q>0$ such that $\dot{P}+A^{T} P+P A=-Q$ holds, and thus $E^{T} P E$ can be taken as a Lyapunov function for the error system. In this case, we calculate the time derivative of the augmented Lyapunov function along (17) and (25) as

$$
\begin{aligned}
\dot{V} & =\frac{1}{2} E^{T} P \dot{E}+\frac{1}{2} \dot{E}^{T} P E+\frac{1}{2} E^{T} \dot{P} E+e_{F} \dot{e}_{F} \\
& =-\frac{1}{2} E^{T} Q E+E^{T} P B e_{F}-\frac{1}{k} e_{F}^{2}+e_{F} \dot{d} \\
& \leq-\frac{1}{2}\left(\lambda_{\min }(Q)-\frac{\eta}{2}\right)\|E\|^{2}-\left(\frac{1}{k}-\frac{1+\|P B\|^{2}}{2 \eta}\right) e_{F}^{2}+\frac{\eta \zeta^{2}}{2} \\
& \leq-\alpha V+\beta,
\end{aligned}
$$

where $\eta>0$ is a positive constant from Young's inequality, $a=\min \left\{\left(\lambda_{\min }(Q)-\eta / 2\right) / \lambda_{\max }(P), 2\left(1 / k-\left(1+\|P B\|^{2}\right) / 2 \eta\right)\right\}$, and $\beta=\eta \zeta^{2} / 2$ are positive constants for appropriately selected parameters $\eta \leq 2 \lambda_{\text {min }}(Q)$ and $k \leq 2 \eta /\left(1+\|P B\|^{2}\right)$. This implies that $V(t) \leq e^{-a t} V(0)+\eta^{2} \zeta^{2} / 2$; thus, the control errors $e, e_{i}$ and the estimator error $e_{F}$ will exponentially converge to a compact small set $\Omega:=\left\{e, e_{F}|| e \mid\right.$ $\left.\leq \eta \zeta,\left|e_{i}\right| \leq \eta \zeta,\left|e_{F}\right| \leq \eta \zeta\right\}$. It is clear that $\lim _{t \rightarrow \infty} e(t)=$ $0, \lim _{t \longrightarrow \infty} e_{i}(t)=0$, and $\lim _{t \longrightarrow \infty} e_{F}(t)=0$ hold for $\eta \longrightarrow 0$ 


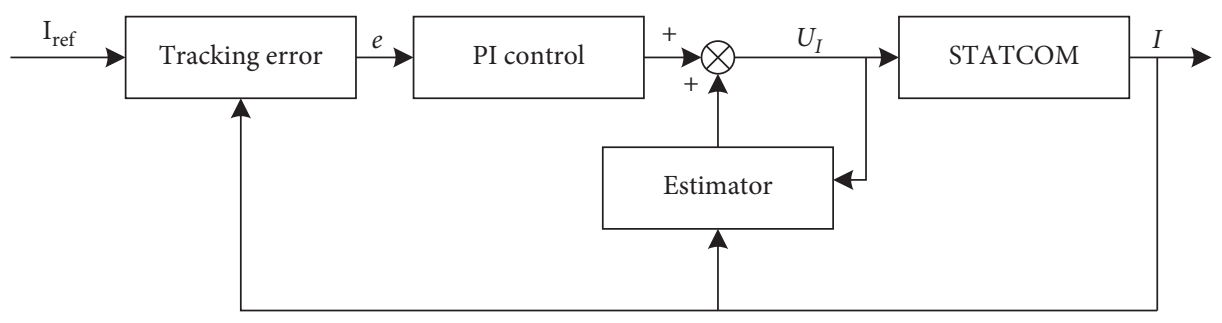

Figure 4: Control scheme of PI + USDE.

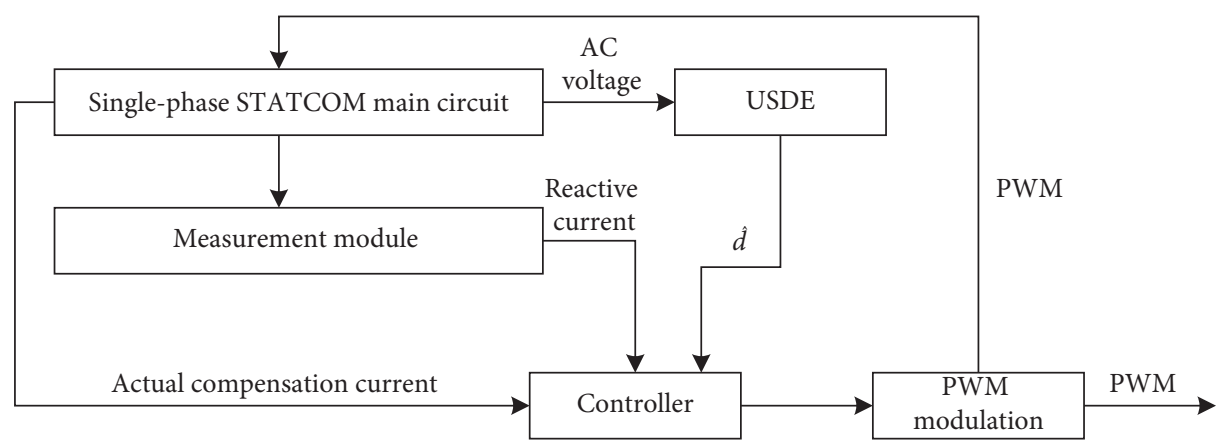

FIGURE 5: The proposed control block diagram for simulation.

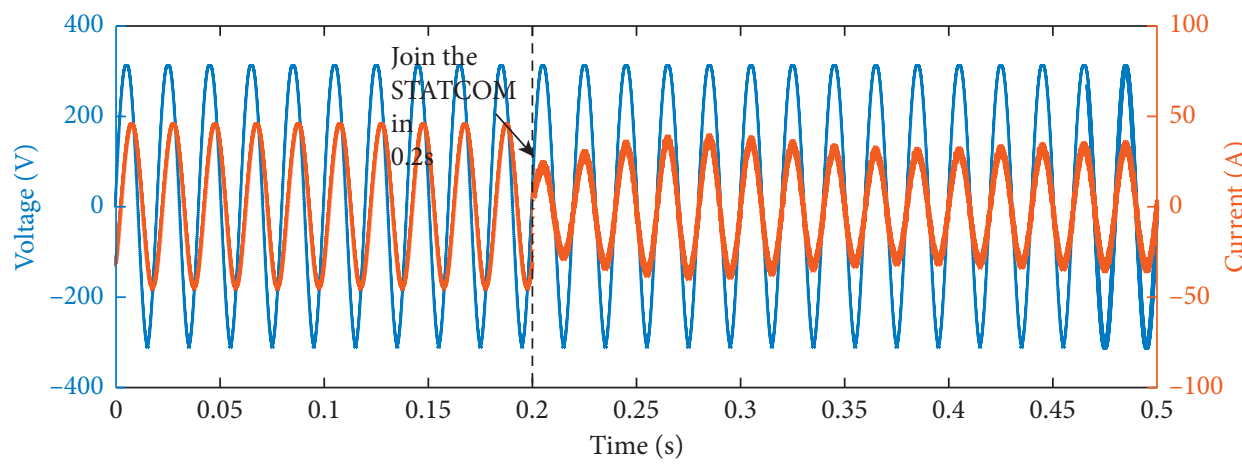

Voltage

Current

FIgURE 6: The waveforms of voltage and current on the grid side.

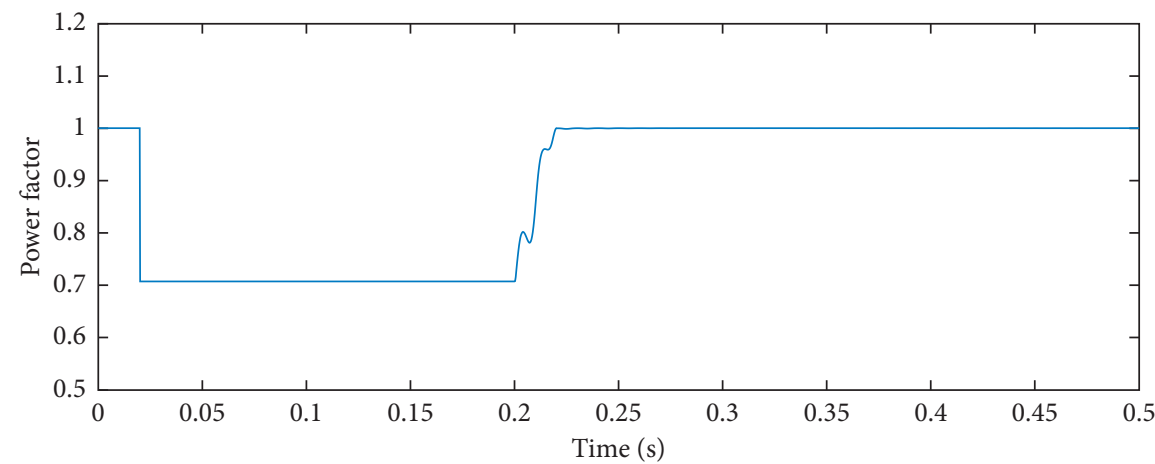

_ The power factor

FIgURE 7: The power factor. 


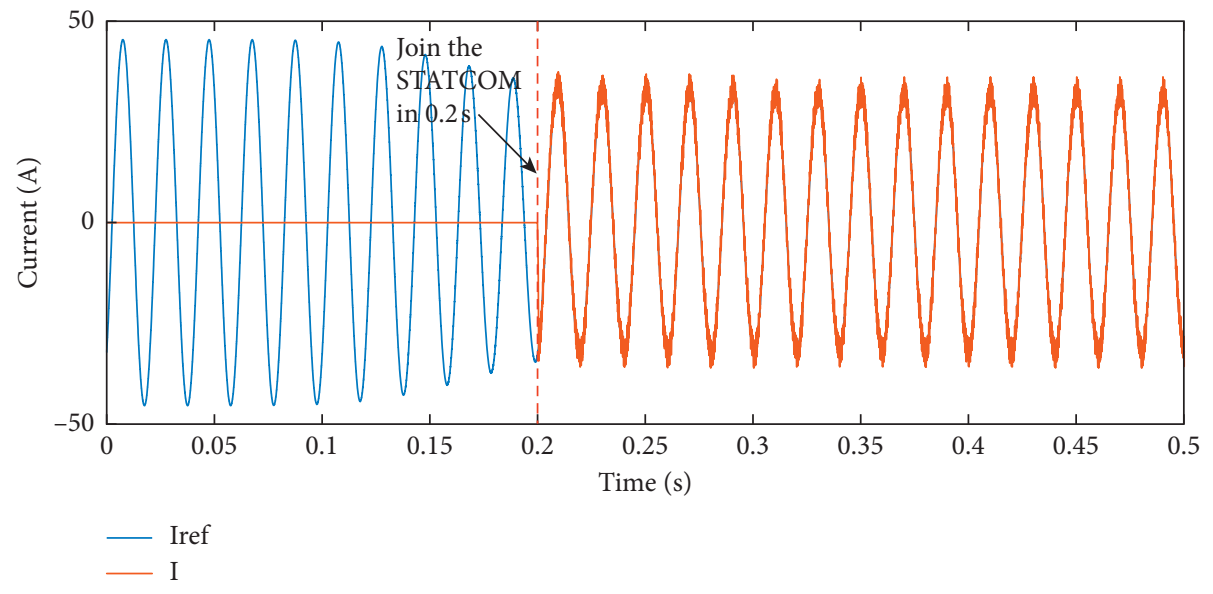

FIGURE 8: Current profile with composite control (PI + USDE).

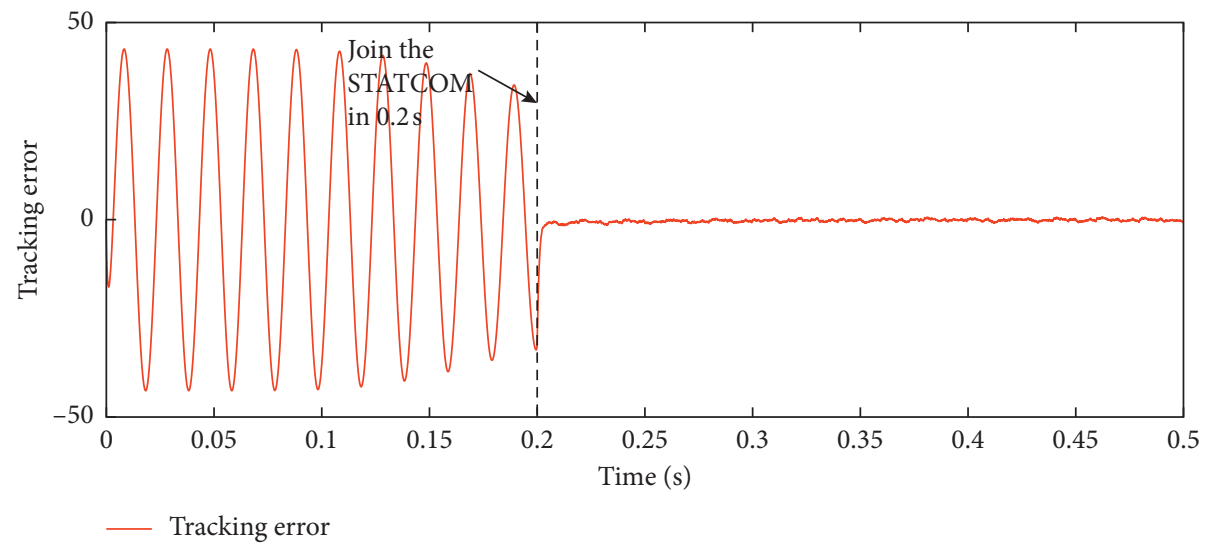

Figure 9: Current tracking error with composite control (PI + USDE).

and/or $\zeta \longrightarrow 0$, for which $k$ is adequately small and/or $d$ is a constant and thus the bound of $|d|$ is $\zeta=0$. This completes the proof.

As shown in the above proof, PI control is used to guarantee the stability of the STATCOM current control system. Then, the estimation $\widehat{d}$ is taken as an extra-feedforward compensation to achieve disturbance rejection and thus better performance. In this respect, this idea brings a two-degree-of-freedom control structure in which the design of the USDE is independent of the PI control, and thus, even in the worst case without the compensator, the controlled system is still stable. Hence, the proposed estimator can be combined with other STATCOM controllers to achieve better control response.

\section{Simulation Results and Analysis}

Recently, STATCOM has been extended to the compensation of distribution systems. The purpose of this paper is to design a controller, which can control the current of STATCOM, so as to complete the compensation of the distribution system. To verify the effectiveness of the system model and the control method proposed in this paper, we build a simulation model based on Matlab/Simulink. In the systems, the electric locomotive load is a typical single-phase load, so that we use the resistance and inductance load to simulate the inductive load of electric locomotive. The whole simulation model consists of three parts: main circuit, controller, and measurement module. The function of the measurement module is to detect the reactive current in the load. The parameters of the system used in the simulation are given as follows: the effective value of grid phase voltage $U_{s}=220 \mathrm{~V}$, the frequency is $50 \mathrm{~Hz}$, the connected inductance $L=9 \mathrm{mH}$, the inductive reactive power of the load is 5000 Var, the DC side capacitance $C=350 \mu \mathrm{F}$, and the capacitor voltage $U_{d c}=700 \mathrm{~V}$. To show the structure of the proposed STATCOM control system, the diagram of the built Simulink model is given in Figure 5.

The PI controller parameters are set as follows: the proportional gain $k_{p}=300$ and the integral gain $k_{i}=13$. Furthermore, the filter constant of USDE is $k=0.001$. In order to test the effectiveness of STATCOM reactive power compensation with/without the proposed control method, we take STATCOM into the load circuit at $0.2 \mathrm{~s}$ through a breaker. Moreover, to further show the efficacy of the proposed approach, a sliding mode observer used in [39] is also tested for comparison in terms of estimating the 


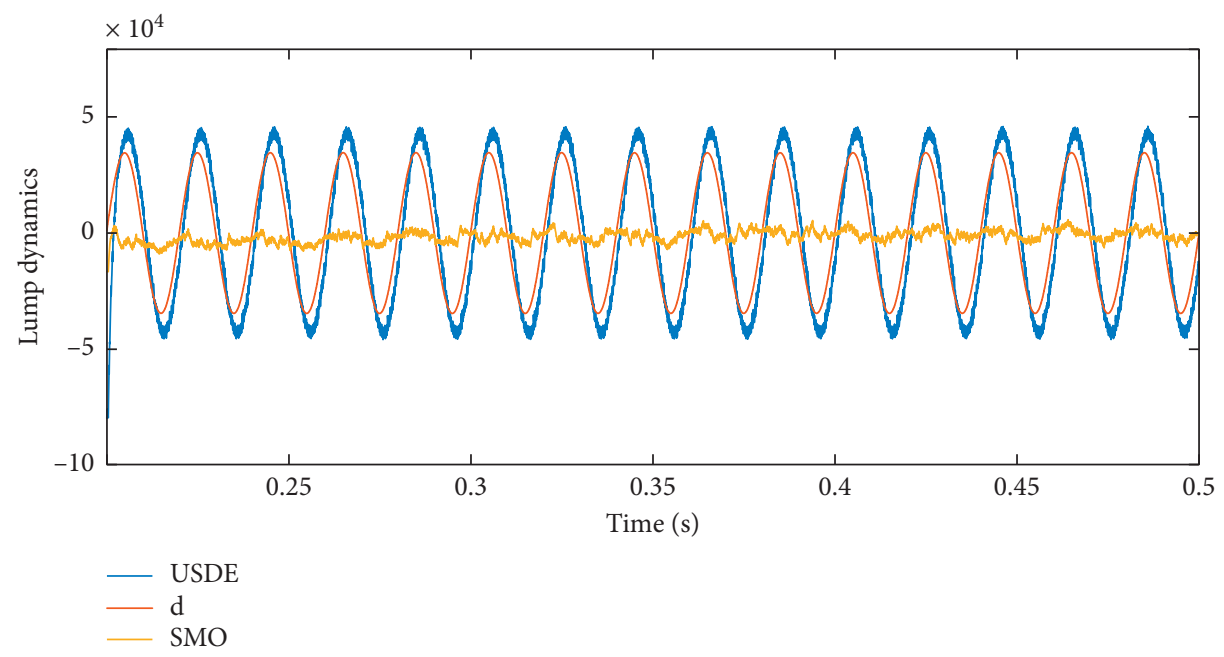

FIGURE 10: Estimation performance of USDE and SMO.

unknown dynamics $d$, and the parameters used in the sliding mode observer are set as $k=0.01$ and $\lambda=150$.

When the inductive load is set to $5000 \mathrm{Var}$, the waveforms of voltage and current on the grid side are shown in Figure 6. By comparing the waveforms before and after $0.2 \mathrm{~s}$, we can find that before putting the device into the operation as the load, the systems are inductive, and the inductive reactive power needs to be absorbed from the grid side. It is clear that the system current lags behind the system voltage, such that the power factor is very low. Nevertheless, after completing the reactive current compensation for the STATCOM, the voltage and current are in the same phase and thus the power factor also increases. Hence, we can find in Figure 7 that the power factor increases from about 0.7 to almost ideal value of 1 . The current tracking result is shown in Figure 8, where the proposed composite control with the PI control and USDE can achieve satisfactory tracking response. The current tracking error is given in Figure 9, which shows that the steady-state error converges to 0 after putting the STATCOM into operation. Finally, the profiles of the estimated dynamics with the USDE and the SMO are given in Figure 10, which indicate that better estimation performance can be achieved by using USDE than that of SMO.

From the above simulation results, we can claim that for the electric locomotive system, the proposed composite control strategy with the USDE and PI controller can reduce the error of current fluctuations and realize more efficient reactive power compensation.

\section{Conclusion}

In this paper, the reactive power compensation of STAT$\mathrm{COM}$ is reformulated as an equivalent tracking control for the required reactive current. We first construct a model of a single-phase STATCOM based on its structure and the operation principle of STATCOM. Then, a new USDE is proposed to address the lumped unknown dynamics in the STATCOM model. With the suggested USDE superimposed on a standard PI control, a composite control structure can be derived. This brings a two-degree-of-freedom control structure in which the design of the USDE is independent of the PI control, and thus even in the worst case without the compensator, the controlled system is still stable. The convergence analysis of both the estimation error and control error is rigorously studied. Finally, numerical simulations are given to support the theoretical claims and show the effectiveness of the proposed method.

\section{Data Availability}

Data were curated by the authors and are available upon request.

\section{Conflicts of Interest}

The authors declare that there are no conflicts of interest regarding the publication of this paper.

\section{References}

[1] C. Mu, Y. Tang, and H. He, "Improved sliding mode design for load frequency control of power system integrated an adaptive learning strategy," IEEE Transactions on Industrial Electronics, vol. 64, no. 8, pp. 6742-6751, 2017.

[2] Y. Tang, H. He, J. Wen, and J. Liu, "Power system stability control for a wind farm based on adaptive dynamic programming," IEEE Transactions on Smart Grid, vol. 6, no. 1, pp. 166-177, 2015.

[3] H. A. Soodi and A. M. Vural, "Single phase nine-level convertor based STATCOM for reactive power compensation and power factor correlation," in Proceedings of the 2018 International Conference on Engineering Technology and Their Applications (IICETA), pp. 19-24, Al-Najaf, Iraq, May 2018.

[4] B. Singh, B. N. Singh, A. Chandra, K. Al-Haddad, A. Pandey, and D. P. Kothari, "A review of single-phase improved power quality ac dc converters," IEEE Transactions on Industrial Electronics, vol. 50, no. 5, pp. 962-981, 2003.

[5] S. Mariethoz and A. C. Rufer, "Open loop and closed loop spectral frequency active filtering," IEEE Transactions on Power Electronics, vol. 17, no. 4, pp. 564-573, 2002. 
[6] J. Yang and Z. Wang, Harmonic Suppression and Reactive Power Compensation, China Machine Press, Beijing, China, 1998, in Chinese.

[7] J. A. Barrena, L. Marroyo, M. Á. Rodriguez Vidal, and J. R. Torrealday Apraiz, "Individual voltage balancing strategy for PWM cascaded H-bridge converter-based STATCOM," IEEE Transactions on Industrial Electronics, vol. 55, no. 1, pp. 21-29, 2008.

[8] E. Babaei, "A cascade multilevel converter topology with reduced number of switches," IEEE Transactions on Power Electronics, vol. 23, no. 6, pp. 2657-2664, 2008.

[9] W.-H. Liu, Q. Song, L.-T. Teng, W. Wang, W.-H. WEI, and J.-C. GENG, "Balancing control of DC voltages of 50MVA STATCOM based on cascade multilevel inverters," Proceedings of the CSEE, vol. 24, pp. 145-150, 2004.

[10] Q. Song, W. Liu, and Z. Yuan, "Multilevel optimal modulation and dynamic control strategies for STATCOMs using cascaded multilevel inverters," IEEE Transactions on Power Delivery, vol. 22, no. 3, pp. 1937-1946, 2007.

[11] D. Jiang and Z. Zhang, "Control scheme of decoupled state feedback linearization of single-phase $\mathrm{H}$-bridge cascaded STATCOM," Power System Technology, vol. 11, pp. 1-14, 2011.

[12] X. Wang, J. Lin, L. Teng, and K. Wang, "Current control strategy of chain circuit STATCOM in d-q-0 coordinates," Zhongguo Dianji Gongcheng Xuebao(Proceedings of the Chinese Society of Electrical Engineering), vol. 32, no. 15, pp. 48-54, 2012.

[13] H. Akagi, S. Inoue, and T. Yoshii, "Control and performance of a transformerless cascade PWM STATCOM with star configuration," IEEE Transactions on Industry Applications, vol. 43, no. 4, pp. 1041-1049, 2007.

[14] J. Shi, W. Gou, H. Yuan, T. Zhao, and A. Q. Huang, "Research on voltage and power balance control for cascaded modular solid-state transformer," IEEE Transactions on Power Electronics, vol. 26, no. 4, pp. 1154-1166, 2011.

[15] X. She, A. Q. Huang, and G. Wang, "3-D space modulation with voltage balancing capability for a cascaded seven-level converter in a solid-state transformer," IEEE Transactions on Power Electronics, vol. 26, no. 12, pp. 3778-3789, 2011.

[16] L. Wang, D. Zhang, Y. Wang, B. Wu, and H. S. Athab, "Power and voltage balance control of a novel three-phase solid-state transformer using multilevel cascaded $\mathrm{H}$-bridge inverters for microgrid applications," IEEE Transactions on Power Electronics, vol. 31, no. 4, pp. 3289-3301, 2016.

[17] C. Zhao, D. Dujic, A. Mester et al., "Power electronic traction transformer-medium voltage prototype," IEEE Transactions on Industrial Electronics, vol. 61, no. 7, pp. 3257-3268, 2014.

[18] D.-H. Lee, "Design and direct field current control scheme of a synchronous generator with PM exciter based on the reference frequency," IET Electric Power Applications, vol. 13, no. 8, pp. 1150-1156, 2019.

[19] S. K. Dash, G. Panda, P. K. Ray, and S. S. Pujari, "Realization of active power filter based on indirect current control algorithm using Xilinx system generator for harmonic elimination," International Journal of Electrical Power \& Energy Systems, vol. 74, pp. 420-428, 2016.

[20] K. D. E. Kerrouche, L. Wang, A. Mezouar, L. Boumediene, and A. Van Den Bossche, "Fractional-order sliding mode control for D-STATCOM connected wind farm based DFIG under voltage unbalanced," Arabian Journal for Science and Engineering, vol. 44, no. 3, pp. 2265-2280, 2019.

[21] G. Farivar, C. D. Townsend, B. Hredzak, J. Pou, and V. G. Agelidis, "Passive reactor compensated cascaded H-bridge multilevel LC-StatCom," IEEE Transactions on Power Electronics, vol. 32, no. 11, pp. 8338-8348, 2017.
[22] Q. M. Zhu, D. Y. Zhao, and J. Zhang, "A general U-block model-based design procedure for nonlinear polynomial control systems," International Journal of Systems Science, vol. 47, no. 14, pp. 3465-3475, 2016.

[23] X. Geng, Q. Zhu, T. Liu, and J. Na, "U-model based predictive control for nonlinear processes with input delay," Journal of Process Control, vol. 75, pp. 156-170, 2019.

[24] Q. Zhu, W. Zhang, J. Zhang, and B. Sun, "U-neural networkenhanced control of nonlinear dynamic systems," Neurocomputing, vol. 352, pp. 12-21, 2019.

[25] Q. Zhu, L. Liu, W. Zhang, and S. Li, "Control of complex nonlinear dynamic rational systems," Complexity, vol. 2018, Article ID 8953035, 12 pages, 2018.

[26] Q. M. Zhu and L. Z. Guo, "A pole placement controller for non-linear dynamic plants," Proceedings of the Institution of Mechanical Engineers, Part I: Journal of Systems and Control Engineering, vol. 216, no. 6, pp. 467-476, 2002.

[27] H. K. Khalil, "Cascade high-gain observers in output feedback control," Automatica, vol. 80, pp. 110-118, 2017.

[28] F. Smida, S. Hadj Saï, and F. M'sahli, "Robust high-gain observers based liquid levels and leakage flow rate estimation," Journal of Control Science and Engineering, vol. 2018, Article ID 8793284, 8 pages, 2018.

[29] F. Allahverdi, A. Ramezani, and M. Forouzanfar, "Sensor fault detection and isolation for a class of uncertain nonlinear system using sliding mode observers," Automatika, vol. 61, no. 2, pp. 219-228, 2020.

[30] H. Wang, B. Su, Y. Wang, and J. Gao, "Adaptive sliding mode fixed-time tracking control based on fixed-time sliding mode disturbance observer with dead-zone input," Complexity, vol. 2019, Article ID 8951382, 14 pages, 2019.

[31] K. Ohishi, M. Nakao, K. Ohnishi, and K. Miyachi, "Microprocessor-controlled DC motor for load-insensitive position servo system," IEEE Transactions on Industrial Electronics, vol. IE-34, no. 1, pp. 44-49, 1987.

[32] W.-H. Chen, D. J. Ballance, P. J. Gawthrop, and J. O’Reilly, “A nonlinear disturbance observer for robotic manipulators," IEEE Transactions on Industrial Electronics, vol. 47, no. 4, pp. 932-938, 2000.

[33] J. Han, "From PID to active disturbance rejection control," IEEE Transactions on Industrial Electronics, vol. 56, no. 3, pp. 900-906, 2009.

[34] Y. Guan and M. Saif, "A novel approach to the design of unknown input observers," IEEE Transactions on Automatic Control, vol. 36, no. 5, pp. 632-635, 1991.

[35] J. Y. Zhaoan Wang, Harmonic Suppression and Reactive Power Compensation, China Machine Press, Beijing, China, 1998.

[36] J. Na, J. Yang, S. Wang, G. Gao, and C. Yang, "Unknown dynamics estimator-based output-feedback control for nonlinear pure-feedback systems," IEEE Transactions on Systems, Man, and Cybernetics: Systems, pp. 1-12, 2019.

[37] J. Na, A. S. Chen, Y. Huang et al., "Air-fuel ratio control of spark ignition engines with unknown system dynamics estimator: theory and experiments," IEEE Transactions on Control Systems Technology, pp. 1-8, 2019.

[38] G.-J. Wang, C.-T. Fong, and K. J. Chang, "Neural-networkbased self-tuning PI controller for precise motion control of PMAC motors," IEEE Transactions on Industrial Electronics, vol. 48, no. 2, pp. 408-415, 2001.

[39] J. Na, A. S. Chen, G. Herrmann, R. Burke, and C. Brace, "Vehicle engine torque estimation via unknown input observer and adaptive parameter estimation," IEEE Transactions on Vehicular Technology, vol. 67, no. 1, pp. 409-422, 2018. 